\section{Cuadernos de} Investigación Histórica

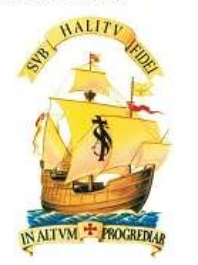

Cuadernos de Investigación Histórica No 36

La emperatriz Eugenia de Montijo: 100 años de la muerte de una española universal Año: 2020

DOI: https://doi.org/10.51743/cih.91

\title{
EUGENIA DE MONTIJO: \\ MUJER Y REGENTE. SU PAPEL POLÍTICO VISTO \\ POR LA PRENSA ESPAÑOLA
}

EUGENIA DE MONTIJO: WOMAN AND REGENT. HIS POLITICAL ROLE SEEN BY THE SPANISH PRESS

CRISTINA BARREIRO

Universidad CEU-San Pablo

\section{RESUMEN}

En 1853 se convirtió por matrimonio en Emperatriz de los Franceses. El ascenso social de la española provocó un aluvión de informaciones en la Prensa ensalzando las bondades de la elegida por Napoleón III. Sus vínculos con la aristocracia española -su madre había tratado de emparentarla con el Duque de Sesto- y el papel de su hermana Paca, Duquesa de Alba, hacían de Eugenia de Guzmán y Portocarrero una candidata diferente a cuantas "matrimoniables" pudiesen haberse sospechado. No poseía en Francia familia a quien colmar de honores y dignidades, como el propio Emperador puso de manifiesto cuando en 1853 presentó a su prometida a las corporaciones oficiales del Estado. A priori su posición podría parecer limitada al papel institucional conferido por su nuevo rango y reducido a tareas de corte social o asistencial, que también desempeñará con solvencia. Sin embargo las circunstancias estratégicomilitares del III Imperio Francés, así como el propio carácter de la protagonista, llevarán a la Emperatriz Eugenia a ocupar puestos notables de responsabilidad política.

Palabras clave: Eugenia de Montijo, emperador Napoleón Bonaparte, Napoleón III, emperatriz 


\begin{abstract}
In 1853 she became Empress of the French by marriage. The social rise of the Spanish woman caused a flood of information in the Press extolling the benefits of the one chosen by Napoleon III. Her links with the Spanish aristocracy - her mother had tried to make her related to the Duke of Sesto and the role of her sister Paca, Duchess of Alba, made Eugenia de Guzmán and Portocarrero a different candidate than many " marriages "could have been suspected. She had no family in France to showcase honor and dignity, as the Emperor himself made clear when in 1853 he presented his fiancée to the official state corporations. A priori, her position could seem limited to the institutional role conferred by her new rank and reduced to tasks of a social or welfare nature, which she will also perform with solvency. However, the strategic-military circumstances of the Third French Empire, as well as the character of the protagonist, will lead the Empress Eugenia to occupy notable positions of political responsibility.
\end{abstract}

Keywords: Eugenia de Montijo, emperor Napoleon Bonaparte, Napoleon III, empress

EN 1853 SE CONVIRTIÓ POR MATRIMONIO en Emperatriz de los Franceses. El ascenso social de la española provocó un aluvión de informaciones en la Prensa ensalzando las bondades de la elegida por Napoleón III. Sus vínculos con la aristocracia española -su madre había tratado de emparentarla con el Duque de Sesto- y el papel de su hermana Paca, Duquesa de Alba, hacían de Eugenia de Guzmán y Portocarrero una candidata diferente a cuantas "matrimoniables" pudiesen haberse sospechado. No poseía en Francia familia a quien colmar de honores y dignidades, como el propio Emperador puso de manifiesto cuando en 1853 presentó a su prometida a las corporaciones oficiales del Estado. A priori su posición podría parecer limitada al papel institucional conferido por su nuevo rango y reducido a tareas de corte social o asistencial, que también desempeñará con solvencia. Sin embargo las circunstancias estratégico-militares del III Imperio Francés, así como el propio carácter de la protagonista, llevarán a la Emperatriz Eugenia a ocupar puestos notables de responsabilidad política. Napoleón III había prometido un reinado de paz, pero durante su mandato tuvieron lugar alianzas bélicas, expediciones imperialistas y guerras coloniales. Su modelo ecléctico político ha sido definido como de una "democracia plebiscitaria" un tanto ensombrecido por el espíritu quimérico y soñador de su protagonista a quien se atribuye, quizá, la mejor descripción de su sistema de gobierno; 
¿Qué clase de Gobierno es el mío? La emperatriz es legitimista. Napoleón Jerónimo (sobrino del emperador), republicano; Morny orleanista; yo mismo un socialista. ¡El único bonapartista es Persigny y está loco!

Durante su matrimonio Eugenia se convirtió en Regente en tres ocasiones y su papel superó las expectativas inicialmente depositadas en la atractiva noble española ${ }^{1}$. Atención aparte merecería su particular empeño en la cuestión mexicana con la creación del Imperio del Archiduque Maximiliano, en lo que supondría uno de los mayores errores estratégicos de Francia y punto de inflexión en la popularidad de la pareja.

¿Cuál fue la reacción de los órganos periodísticos españoles ante tan inesperado desafío? Europa vivía todavía los momentos de cambio derivados de las olas revolucionarias que habían alterado no sólo los modelos políticos sino también la configuración geográfica y cultural del viejo continente. Desde una perspectiva distante -y hoy contemporánea- podrían entenderse los años 50 y 60 como unas décadas en las que mujeres, convertidas por herencias dinásticas en soberanas, tomaban el timón de sus Estados. Victoria de Inglaterra e Isabel II de Borbón llevaban sobre su cabezas la responsabilidad de naciones en transformación. Pero ¿hubo interacciones entre este nuevo marco contextual y la mano política de Eugenia de Montijo? ¿Supo la Prensa utilizar la nueva posición de la Emperatriz en una comparativa con la situación política isabelina previa al exilio de 1868 ? En agosto de 1870, cuando se adivinaba una próxima derrota francesa frente a Bismark, el periódico satírico, antimonárquico y anticlerical, Gil Blas publicará;

La misma doña Isabel de Borbón que un mes atrás se creía desgraciada comparando su suerte con la de su antigua servidora doña Eugenia, ha visto de pronto cambiada la suerte de la emperatriz como si por escotillón la hubiesen despojado de su manto, corona y prestigio ${ }^{2}$

El lenguaje de la época nos sigue hablando de las "debilidades propias de su sexo", el de una mujer, la marquesa de Moya, a la que el matrimonio, en su caso,

\footnotetext{
${ }^{1}$ Existen buenas aproximaciones biográficas a la figura de Eugenia de Montijo aunque algunas con un carácter más divulgativo que científico. El trabajo de Almudena ARTEAGA, Eugenia de Montijo, Barcelona: ed. Martínez Roca, 2000 es una novela histórica y la de la periodista Pilar, EYRE, Pasión Imperial. La vida secreta de la Emperatriz Eugenia de Montijo, la española que sedujo a Napoleón III y conquistó Francia, Madrid: La Esfera, 2010, aunque documentada, puede acercarse al folletín histórico. El ensayo de Fernando, DÍAZ-PLAJA: Eugenia de Montijo, emperatriz de los franceses, Barcelona: Planeta, 1993, acerca al personaje a través de las cartas personales de Eugenia que se conservar en el Archivo de la Casa de Alba y presenta una visión cercana al lector. En una línea biográfica ya clásica, resultan de referencia las detalladas obras; D.,DUFF, D. Eugenia de Montijo y Napoleón III, Madrid: Rial, 1981 e I. MARGARIT, Eugenia de Montijo y Napoleón III. Madrid, Barcelona: Plaza\&Janés, 1999. También puede verse el trabajo de Octave AUBRY, Eugenia de Montijo, Barcelona: Joaquín Gil, 1943, actualmente difícil de encontrar. Copiosas referencias a la Emperatriz Eugenia encontramos en; Imbert SAINT-AMAND, Napoleón III, Barcelona: Montaner y Simon Editores, 1898.

${ }^{2}$ Gil Blas (18 agosto 1870)
} 
iba a deparar altas decisiones de mando. El británico Morning Post abrirá incluso un debate sobre el papel de la mujer en el poder: ¿reinar y gobernar? recogido por gran parte de los diarios españoles. Todos estos aspectos, nos permitirán avanzar en el conocimiento no solo de una época de fuertes contradicciones en el papel de Francia en el plano internacional sino sobre todo, en la visión que se ofreció en España de la condesa granadina que se había convertido en Emperatriz de los Franceses. Porque entendemos que esta manera de mirar lo pequeño se convierte en un método para aproximarse a la historia.

La investigación se ha construido sobre la base de la Prensa española publicada en 1859, 1865 y 1870, periodos en los que Eugenia de Montijo asumía eventualmente la Regencia en nombre de su esposo. La campaña de Italia, el viaje de Napoleón III a Argelia y la Guerra Franco-Prusiana que terminará con el Imperio, llevarán a la española a dirigir temporalmente el destino de Francia. Para este trabajo se ha visto la Prensa digitalizada de estos años, disponible en la Hemeroteca Digital de la Biblioteca Nacional así como en el Portal de Prensa Histórica y los fondos que se conservan en Memoria de Madrid, resultado de la digitalización de la Hemeroteca Municipal. Se ha tomado como referencia además el catálogo Hartzenbusch para identificar muchas de las publicaciones referidas ${ }^{3}$. Hay que constatar una clara diferencia entre los periódicos que se publicaban en España durante el periodo isabelino posterior a 1850 -etapa de depósitos previos, censura y sanciones donde la aparición de la llamada Prensa informativa o noticiera viene a desbancar a los tradicionales periódicos de partido- y la irrupción de un nuevo periodismo posterior a La Gloriosa, marcado por las libertades devenidas de la Constitución de 1869 y en el que abundan diarios de carácter progresista, republicano y federal. Los satíricos Padre Cobos y sobre todo Gil Blas, forman también parte del elenco analizado. La agencia Havas y el parisino Le Moniteur

${ }^{3} \mathrm{https}: / /$ archive.org/details/apuntesparaunca00hartgoog $/$ page $/ \mathrm{n} 1$ 99 $/$ mode $/ 2$ up?q=\%22El + Estado $\% 22$.

Una interpretación general de la Prensa en el periodo isabelino encontramos en PIZARROSO, Alejandro: Historia de la Prensa. "Entre moderantismo y progresismo". Madrid, Ramón Areces, 1994. pp.275-280. Sobre la Prensa en el Sexenio Democrático continúa siendo un trabajo de referencia Antonio CHECA GODOY, El ejercicio de la libertad. La Prensa española en el Sexenio Revolucionario (1868-1874), Madrid: Biblioteca Nueva, 2006. Sobre la Prensa satírica y también del mismo autor; Antonio CHECA GODOY, “Auge y crisis de la prensa satírica española en el Sexenio Revolucionario (1868-1874) “, El Argonauta español [En ligne], 13 | 2016, mis en ligne le 30 janvier 2016, consulté le 24 juillet 2020.

https://journals.openedition.org/argonauta/2335.

Para cuestiones referidas a la situación de la Prensa en Francia durante el Imperio puede verse: R. BELLET, Presse et journalisme sous le Second Empire, París: Armand Colin, 1967. Según este trabajo los periódicos de mayor tirada en los años iniciales del Imperio eran La Presse, Le Moniteur Universel y Le Constitutionnel. Conforme avanzamos en la evolución del periodo e irrumpe en Francia el fenómeno de la prensa de masas se produce un vuelco en el panorama general de la Prensa que lleva a Le Petit Journal a ocupar la primera posición seguido de Le Figaro y ya muy por debajo Le Siècle y Le Moniteur Universel. 
Universel monopolizaban gran parte de las informaciones del Imperio mientras que el telégrafo y el correo eran las vías principales de recepción de noticias. Las cartas que se recibían en las redacciones, de particulares, soldados o redactores-corresponsales, constituyen también una fuente principal de documentación. Todos estos materiales se han puesto en relación con las informaciones sustraídas de la revisión bibliográfica sobre el personaje, que nos ha permitido aproximarnos al escenario temporal en el que se desarrolla el punto de vista ofrecido sobre la protagonista.

\section{EUGENIA, NAPOLEÓN Y LA CAMPAÑa DE ITALIA (MAYO-JULIO 1859)}

Historiográficamente se ha debatido mucho sobre la diferencia de criterios que existía entre la Emperatriz y Napoleón III respecto a la cuestión italiana. Eugenia no compartía la causa de la unificación defendida entonces por su esposo, posiblemente influenciada por sus profundas convicciones católicas que adelantaban un posible enfrentamiento con los Estados Pontificios. Es probable también que en el ánimo de la española influyese el intento de asesinato de la pareja imperial a manos de un independentista italiano en enero de 1858. Pero lo cierto es que por esas fechas terminaba en Francia la etapa de gobierno autoritario, continuista de la política iniciada en diciembre de $1851^{4}$.

En el mes de abril de 1859, la Prensa española se hacía eco de un rumor por el que Napoleón III abandonaría París para participar en la campaña entre sardos y austriacos en la conocida como segunda guerra de independencia italiana que enfrentaba al Reino del Piamonte con el Imperio Austro-húngaro. En el Manifiesto de 3 de mayo, el Emperador decía: "Dejo en Francia a la Emperatriz y a mi hijo. Secundada por la experiencia y las luces del último hermano del Emperador, ella sabrá elevarse a la altura de su misión". Por Decreto, la Emperatriz Eugenia asumía por primera vez la Regencia asesorada por los miembros que constituían su Consejo Privado integrado por el cardenal Morlot, el duque de Malakoff, M. Aquiles Fould, M. Tropong, el conde de Morny, M. Baroche y el conde de Presigny. Luego se unirían el mariscal Vaillant y el conde Waleswky5. Quedaba también asistida por el Príncipe Napoleón, cercano consejero de su primo. El día

\footnotetext{
${ }^{4}$ Interesante síntesis sobre la posición del Emperador y del II Imperio Francés en la cuestión italiana encontramos en; J. CHAVES PALACIOS. y F. LÓPEZ MORA, El Segundo Imperio Francés (1852-1870), Córdoba: Servicios de Publicaciones de la Universidad de Córdoba, 2012. pp.102-105. Llama la atención sin embargo, cómo en este trabajo no se hace alusión a las intervenciones de la Emperatriz Eugenia en los asuntos políticos de la época. Para conocer los diferentes enfoques que se dan sobre la visión de la Emperatriz en la cuestión italiana puede verse Fernando DIAZ-PLAJA, F: Eugenia de Montijo, pp. 88-101. Como obras contextuales del periodo; F. PAEZ-CAMINO y P. LLORENTE HERRERO, Francia: el Segundo Imperio y la Tercera República, Madrid: Akal, 1986 y P. MIQUEL, P., Le second Empire. París: Perrin, 2008.

${ }^{5}$ Diario Oficial de México (19 junio 1859).
} 
10, el Emperador partía de París para ponerse al frente de los ejércitos aliados. Senado, cuerpo legislativo y Consejo de Estado, respaldaron la decisión de Napoleón III.

Hasta esa fecha, las informaciones que se han recogido en La Época, El Clamor Público, La España, La Iberia o La Esperanza apenas habían hecho referencia a una fiesta de sociedad ofrecida en los aristocráticos salones madrileños de la condesa-madre de Montijo, el proyectado viaje del matrimonio regio a Inglaterra para visitar a la Reina Victoria en Osborne o a la banda de la orden de María Luisa que lució la Emperatriz en una recepción diplomática en las Tullerías $^{6}$. No se había resaltado un posible papel político en Eugenia que hasta ese momento, se limitaba a ser una belleza católica española, magnífica amazona y cazadora, que había puesto de moda el terciopelo en los trajes de corte y opuesta a los miriñaques. Es importante señalar, que en estos días gobernaba en España el general Leopoldo O'Donnell quien empezaba a poner en práctica su proyecto de la Unión Liberal en un momento en el que la Guerra de Marruecos iba a situarse como la principal preocupación de la monarquía isabelina. La Prensa, por entonces, dividía sus afectos entre moderados y progresistas -o ministeriales según la configuración del gabinete- aunque opciones de carácter más tradicional como La Esperanza o incluso próximas a cierto reformismo monárquico, encontraban también su espacio. Algunos como El Clamor Público se definían sencillamente como "Periódico Liberal".

Fue una Regencia breve, que apenas llegó a los dos meses, durante la cual la Emperatriz Eugenia dio muestras de cierto sentido de deber político, prudencia y determinación, cualidades que han sido destacadas por todos su biógrafos como muestra del carácter de la española. En este tiempo, en el que se puso a prueba la compleja política exterior del Imperio en la cuestión derivada del inicial proceso unificador piamontés, Napoleón III terminará poniendo freno a sus apoyos turineses en Plombieres, aun cuando su victorioso protagonismo en la Batalla de Magenta pudiese haber hecho pensar implicaciones mayores. El diario progresista $E l$ Clamor Público se refirió desde los primeros momentos al carácter enérgico de la Regente quien dio pruebas "de mucha presencia de espíritu y manifestó en sus palabras grande energía"

${ }^{6}$ El Clamor Público (22 enero 1859) y La España (4 febrero 1959). La Época era un diario moderado de corte aristocrático, El Clamor Público se identificaba con el progresismo, La España ocupaba el ala derecha del Partido Moderado, La Iberia era progresista y La Esperanza era el periódico católico afín al tradicionalismo. De todos ellos sólo La España dejará de publicarse después de "La Gloriosa". Han sido consultados en:

${ }^{h}$ ttp://hemerotecadigital.bne.es/results.vm? $\mathrm{b}=$ search-visible \& $\mathrm{t}=\% 2 \mathrm{Bcreation} \& \mathrm{l}=600 \& \mathrm{l}=$ $700 \& \mathrm{~s}=0$ \& $=1859$ \&lang $=\mathrm{es}$

${ }^{7}$ El Clamor Público (11 y 25 mayo 1859). Como prueba del influyente papel que desempeñaba la correspondencia recibida en las redacciones durante la Guerra, nos encontramos con la decisión 
de su esposo en la política de los Saboya debido a su aferrada espiritualidad y la polémica "cuestión religiosa" que enfrentaría a Italia con el papado. Prueba de ello -años después y cuando Eugenia vuelva a asumir la Regencia con motivo del viaje de Napoleón III a Argel- leeremos en la Prensa la satisfacción de la Emperatriz al recibir en juramento a varios obispos, por la noticias de "reconciliación entre Italia y el Pontificado"s.

Especialmente polémico resultó el artículo de alabanza que El Estado -diario moderado de la noche aparecido y muerto en el mismo 1859 de la mano de Prudencio Naya- con el título "La Emperatriz Eugenia" publicó con motivo del regreso a París del Emperador y en el que aplaudía la eficaz gestión desempeñada por la condesa de Teba durante su ausencia. Todo un tributo de admiración a la española que "modelo de virtudes cristianas" había dedicado su actividad "al alivio de los enfermos y socorro de los pobres" antes de asumir su puesto en el Estado". Desde el momento en el que asumió la Regencia, dirá El Estado;

Francia no ha tenido motivo para echar un momento de menos a su soberano en el régimen interior de sus pueblos. El despacho de los negocios públicos no ha sufrido la menor interrupción; el ejército ha sido puntualmente asistido, a pesar de las enormes exigencias de la situación, y el consejo de Ministros reunido periódicamente en las Tullerías o en Saint-Cloud, no ha tenido ocasión de notar que la silla de la presidencia estaba ocupada por una mujer ${ }^{10}$.

Estas líneas no pueden ser más elogiosas para la figura de Eugenia de Montijo. Pero este artículo de admiración hacia la granadina, no fue siempre bien entendido en los entornos liberales de la España Isabelina de ese verano de 1859 en la que gobernaba un gabinete O'Donnell. Los círculos austro-papistas, como los definió el progresista La Iberia -aunque subtitulado "diario liberal de mañana"- podían sentirse perjudicados por la conducta resuelta de la Emperatriz. La controversia parecía servida. Algunos diarios ministeriales quisieron convertir el artículo en un argumento anti-dinástico estableciendo innecesarias comparaciones $^{11}$. ¿No era quizá el momento para su publicación pues circulaban ru-

del Ministro de Guerra francés, de prohibir a los militares del ejército de Italia, dirigir cartas a los periódicos.

${ }^{8}$ La Correspondencia de España (29 mayo 1965). En su segunda época comenzó a publicarse en 1860 y representa el éxito de un nuevo modelo de Prensa informativa, de empresa y noticiosa. Llegó a convertirse en el periódico de mayor tirada a finales del XIX. Su principal inspirador fue Manuel María de Santa Ana. La ficha completa del diario la encontramos en

http://hemerotecadigital.bne.es/details.vm?q=id:0000000000\&lang=es

${ }^{9}$ El Clamor Público (16 julio 1859)

${ }^{10}$ No se ha localizado el ejemplar original de El Estado en el que se publicó el sonado artículo. Sin embargo si hemos tenido acceso a las reproducciones del mismo que se hicieron en los diarios españoles durante esos días y que fueron foco de la polémica. De esa reproducción se han extraído los párrafos que se insertan en el texto.

${ }^{11}$ La Iberia (28 mayo 1859), La España y El Día (21 julio 1859) 
mores por Madrid de la posible entrada en el Gobierno de Espartero y Olózaga apoyados por la influencia del Emperador de Francia? El periódico moderado La España quiso ver también un intento de interferencia extranjera en los asuntos españoles y no puso reparos a la hora de responder a El Estado en su panegírico a la Emperatriz. De nuevo, la política internacional parecía condicionar la visión española de la Regencia.

La Regente de Francia recibió también las críticas del periódico progresista-catalanista de Barcelona, La Corona, que aunque de limitada tirada, vio con recelo la opinión manifestada por Eugenia al sentir, en el discurso al cuerpo legislativo francés, su corazón "completamente francés"12. Los rumores dirán, más adelante, que la Emperatriz de los franceses ya no dejó de asistir a los Consejos de Ministros presididos por Napoleón.

\section{NAPOLEÓN III EN ARgELIA: REgENCIA Y ACCIÓN SOCIAL (MAYO- JUNIO 1865)}

El domingo 30 de abril de 1965, leemos en los despachos telegráficos publicados en el moderado El Contemporáneo, que Napoleón III se disponía a marchar hacia Argel. Era su segunda visita en el breve espacio de tres años. La situación de la entonces colonia francesa, en plena fase de liberalización del régimen desde el punto de vista político y económico, pasaba por momentos internamente complejos y era "el deseo de enterarse por sí mismo de la situación" lo que le movía a emprender este viaje ${ }^{13}$. El Contemporáneo anunciaba también que su esposa asumiría la presidencia del Consejo Privado del Emperador, aunque no la Regencia "mientras éste no abandone territorio francés"14. Tres días después, por Decreto Imperial, Eugenia de Montijo volvía, por segunda vez durante su matrimonio, a ser proclamada Regente. Tenía treinta y nueve años.

El Imperio se encontraba en una etapa de reformas que si bien no alteraron sustancialmente el régimen, si denotaban deseos de cambio político: lo que al-

${ }^{12}$ La Corona dejó de publicarse tras el exilio de Isabel II.

${ }^{13}$ La Argelia colonia ha merecido escasa atención de la historiografía francesa anterior a la descolonización. Apenas encontramos referencias en el ya clásico trabajo de P. GUIRAI y E. TEMIME, "L'Hisiorioarupliic dii Second Empire". Revue d'Histoire Moderne et Contemporaine. t. XXI. París,:1974, pp. 1-17. En España tenemos los trabajos del catedrático Juan Bautista Vilar Ramírez aunque más centrados en la emigración mediterránea a territorio argelino en el periodo. Puede verse, Juan B. VILAR, Los españoles en la Argelia francesa (1830-1914), Murcia: C.S.I.C. y Secretariado de Publicaciones de la Universidad de Murcia, 1989.

${ }^{14}$ El Contemporáneo (30 abril 1865) y Revista Hispano-Americana (13 mayo 1865). El Contemporáneo era un periódico afín al Partido Moderado y muy contrario a la Unión Liberal de O’Donnell que se publicaba por iniciativa del Marqués de Salamanca. Su último número es del 31 de octubre de 1865. Para su consulta;

http:/hemerotecadigital.bne.es/details.vm?q=id:0003463474\&lang=es 
gunos historiadores han llamado "el Imperio liberal"15. Sin embargo, también es cierto que había comenzado un periodo en el que el matrimonio imperial iba progresivamente perdiendo el aura de popularidad de los lustros iniciales del régimen, declive sólo maquillado por éxito propagandístico que había supuesto la visita de Eugenia a Suez en noviembre de 1869 con motivo de la inauguración del canal.

Resulta interesante comprobar como durante el periodo analizado, la Prensa española recoge muchas de sus informaciones del diario oficial Le Moniteur Universel. Sabemos así que Eugenia firmó el decreto por el que se promulgaban los tratados de comercio y de navegación entre Francia y Prusia o que recibió al Embajador de Turquía y al Ministro plenipotenciario de Estados Unidos, Bigelon, en un momento en el que acababa de producirse el asesinato del Presidente Lincoln ${ }^{16}$. Y también por esta vía nos enteramos de que durante su regencia, Eugenia firmó el Decreto por el que se nombraba a la pintora Rose Bonheur "caballero de la legión de honor", primera mujer condecorada en Francia con esta distinción ${ }^{17}$. Pero la actividad de la Regente traspasó las obligaciones político-económicas inherentes al cargo ya que Eugenia mantuvo todas las responsabilidades de carácter asistencial en las que había implicado desde su matrimonio con Napoleón. En este sentido y a raíz de la polémica suscitada por la denuncia sobre la miserable situación de las prisiones del diputado republicano Jules Simon en el Cuerpo legislativo, Eugenia no dudó en encabezar una campaña de visitas a las cárceles más afectadas como eran la de La Roquette, Mazas o San Lazaro. "Gracias a la iniciativa de una extranjera" -leemos en La Época- se pusieron en marcha diferentes iniciativas para la demolición de "celdas miserables" y corregir las insalubres condiciones de los establecimientos penitenciarios franceses ${ }^{18}$.

La actividad de la Emperatriz durante los meses que duró su Regencia fue recogida por la Prensa como asombrosa y frenética en su actividad. A Eugenia se le atribuyen cualidades políticas de perspicacia, seguridad de juicio y fina inteligencia. Se diría -léemos en el un suelto publicado en El Contemporáneo que recoge informaciones de Gacette Autrichienne- "que había olvidado todas las dulces ocupaciones de la mujer para no pensar más que en sus deberes de soberana que (...) llena a la vez con el alma tierna de la mujer y la mano firme del hombre"19.

Al regreso de Napoleón III de Argel a finales de junio de 1865, el Emperador recuperaba los poderes efectivos del Estado y Eugenia de Montijo volvía

\footnotetext{
${ }^{15}$ Síntesis general del periodo liberalizador del Imperio encontramos en el trabajo; J. CHAVES PALACIOS y F. LÓPEZ MORA, El Segundo Imperio Francés (1852-1870). pp 105-125.

${ }^{16}$ El Contemporáneo (14 mayo 1865).

${ }^{17}$ La Corona (14 junio 1865) y La Época (23 junio 1865)

${ }^{18}$ La Época (28 junio 1865).

${ }^{19}$ El Contemporáneo (4 junio 1865).
} 
a desempeñar su rol como consorte. En esos días, se presentó en el Senado el proyecto de Ley sobre naturalización en Argelia por el cual se concedía la nacionalidad francesa a musulmanes y judíos, si bien el primero continuaba bajo el régimen de la ley musulmana y el segundo sometido a un estatuto personal. Esta decisión, provocó el enfado de los colonos franceses. Sin embargo resulta llamativo comprobar cómo, aún en ese contexto, la española fue propuesta para ocupar la vice-presidencia del Consejo de Estado en sustitución del Príncipe Napoleón. Algunos quisieron ver en esta decisión una "idea continuista" del Emperador: es decir, formar políticamente a su esposa para que si llegado el caso -su fallecimiento antes de que su único hijo alcanzase la mayoría de edad- y tuviese que ocuparse de los asuntos del Estado, estuviese suficientemente formada en los negocios públicos para regir los destinos de Francia. Esta información, dice el progresista La Nación, es recogida vía correspondencia recibida en la redacción del diario ${ }^{20}$. La la mayor parte de las publicaciones españolas también aludieron al debate que se había abierto entre sus colegas franceses acerca de esta cuestión.

La Emperatriz volvió a desempeñar las labores inherentes a su rango como consorte aunque ya sin abandonar el gusto por la influencia política que había desarrollado y que la llevaría a ejercer una presión notable en la cuestión mexicana. A finales de agosto de 1865 la Familia Imperial se trasladó a su residencia de Biarritz con motivo del descanso estival. Como era costumbre desde su llegada al trono, la cercanía con España propiciaba encuentros afectuosos entre ambas casas reinantes. Eugenia mantenía además en Vizcaya su palacio de Arriaga. Los Borbones, en San Sebastián no dudaban en cruzar la frontera por Hendaya para visitar a su amiga española mientras que Eugenia, siempre apegada a su país de origen, manifestó a lo largo de su vida profundo afecto por Isabel II y su familia. Como no podía ser de otro modo, el monárquico La Época daba cumplida información de estos encuentros desplegando todos sus recursos técnicos para facilitar las más precisas noticias a los lectores ${ }^{21}$. La primera visita solía ser la de Napoleón y esposa a San Sebastián, celebrándose los protocolarios encuentros con los Borbones españoles encabezados por la Reina, el Rey Francisco, el Príncipe de Asturias, la Infanta Isabel y el Infante Don Enrique, aunque las recepciones en "villa Eugenia" eran también "brillantes y afectuosísimas" 22.

${ }^{20}$ La Nación (30 junio 1865). Era un veterano periódico progresista que en estas fechas se encontraba bajo la inspiración de Pascual Madoz. Referencias hemerográficas al mismo encontramos en http://hemerotecadigital.bne.es/details.vm?q=id:0026575960\&lang=en

${ }^{21}$ La Época $(9,11$ y 12 septiembre 1865). El tren era el medio de transporte que utilizaban la familia imperial y real para atravesar la frontera entre ambos países.

${ }^{22}$ El Pabellón Nacional (13 septiembre 1865). Era un diario, de poca tirada, adscrito al liberalismo moderado. Puede consultarse en;

https://prensahistorica. mcu.es/es/consulta/registro.do?id=4016 
Eugenia, pese al reuma que le aquejaba, visitó en ese año muchos hospitales atestados de enfermos por la epidemia de cólera que afectaba al país. Era atenta y afectuosa y su presencia desencadenaba "frenético entusiasmo"23. La Familia Imperial donó fondos económicos para tratar de paliar el impacto de la enfermedad. Eugenia de Montijo tomó bajo su protección todos los establecimientos de beneficencia que dependían de la corona con potestad para definir sobre la admisión de enfermos y pobres en esos centros, aun cuando siguiesen bajo la dependencia del Ministerio del Interior, según leemos en el católico La Esperanza ${ }^{24}$. Eugenia siguió recabando fondos para obras diversas como el monumento al fallecido duque de Morny -hermanastro de Luis Napoleón y primer esposo de Sofía Troubetzkoy quien andado el tiempo se convertiría en Duquesa de Sesto- o las obras del Santo Sepulcro de Jerusalén en las que también se implicó directamente.

No podemos olvidar que en octubre de 1865 se celebraría la entrevista entre Bismarck y Napoleón III. Con ello se iniciaba una nueva etapa en historia del II Imperio Francés.

\section{La Emperatriz Eugenia y la Guerra Franco-Prusiana (Julio- AGOSTO 1870)}

De nuevo, volvería por seis semanas a ocupar Eugenia la Regencia con motivo de la Guerra Franco-Prusiana que tanto determinó el futuro de los Emperadores y de la que en ocasiones se ha responsabilizado a la española en sus ímpetus belicosos: falsamente se le ha atribuido la expresión "es mi guerra"25. En 1870 el contexto europeo era complejo: en pleno asalto de las tropas de Garibaldi a los Estados Pontificios para concluir el proceso unificador era ahora Bismark quien se lanzaba a la última fase de su política imperialista. Como leemos en el liberal La Iberia;

Prusia, mejor Bismark, marcha a paso rápido a la unificación alemana para construir de una vez el imperio germánico, trabajo próximo a dar los resultados que con tanto afán como perseverancia ha previsto el gran ministro de Guillermo I $^{26}$

${ }^{23}$ La España (25 octubre 1865).

${ }^{24}$ La Esperanza (19 agosto 1865).

${ }^{25}$ Consideraciones sobre la posición de Eugenia en el conflicto franco-prusiano de 1870 encontramos en Fernando DIAZ-PLAJA, Eugenia de Montijo, emperatriz de los franceses, pp.116-120. Para comprender el auge de la prensa republicana francesa que tanto contribuyó a la caída del II Imperio francés resulta interesante la síntesis que encontramos en J. CHAVES PALACIOS y F. LÓPEZ MORA, El Segundo Imperio Francés (1852-1870), pp. 105-125.

${ }^{26}$ La Iberia (9 marzo 1870) 
En esta Europa cambiante y ante la coyuntura final de la creación del reino de Italia, Eugenia de Montijo ofrecía al Papa Pío IX el "apoyo moral de Francia" en el caso de nueva invasión en el territorio Pontificio por las tropas de Garibaldi ${ }^{27}$. Pero este deseo personal de la "papista Eugenia" no se cumpliría. El II Imperio cada vez estaba más aislado en el contexto internacional.

Francia acogía además desde septiembre de 1868 a los Borbones exiliados a los que "La Gloriosa" había privado del Trono. En París, desde el Palacio del Castilla, trataba de articularse el proceso de una Restauración que devolviese la corona a Isabel, a su hijo Alfonso o incluso al Duque de Montpensier. Periódicos como El Eco del Progreso, que se definía como independiente, se oponían tajantemente a esta posibilidad al considerar estas opciones "incompatibles con la dignidad de España”28. El progresista La Iberia, decía tener constancia de que desde las Tullerías podría haber simpatías manifiestas a los Borbones pero también de que el gobierno francés se mantenía leal al español, que en esos momentos pasaba por el general Prim ${ }^{29}$. En España además, la regencia del General Serrano presionaba a los franceses en la cuestión de Leopoldo Hohenzollerm: para los franceses la proclamación de un rey germánico en el sur de sus fronteras significaba el cerco de su país por sus enemigos tradicionales. La renuncia a la candidatura del trono de España del príncipe alemán desató el desenfreno de la Prensa y las habilidades de Bismark en la manipulación del famoso "telegrama de Ems", aceleró el camino hacia la Guerra. En Francia se respiraba un ambiente belicista y sólo algunos miembros del Cuerpo Legislativo, se opusieron a los créditos de guerra. Mientras, los partidarios de la vuelta al autoritarismo presionaron a favor de la confrontación armada. Y Napoleón III, en la confianza de que una victoria ante Prusia consolidaría el régimen, optó por la guerra.

El 18 de julio, el periódico informativo La Correspondencia Universal confirmaba la salida inmediata del Emperador y su hijo, para la frontera del Rhin. "Los esfuerzos de la diplomacia han sido inútiles, y el cañón de Sadowa resonará pronto" leemos en el católico La Esperanza ${ }^{30}$. Desde este momento, se impuso el silencio a los periódicos franceses sobre las operaciones de guerra. Eugenia quedaba de nuevo al frente del Consejo de Regencia. El Decreto lleva fecha de

\footnotetext{
${ }^{27}$ La Correspondencia Universal y Diario Oficial de Avisos de Madrid (29 julio 1870)

${ }^{28}$ El Eco del Progreso (1 enero 1870). Sobre la situación española en el periodo del Sexenio Democrático y las repercusiones en la política internacional en el contexto Francia/Alemania véase; José María JOVER, La era isabelina y el Sexenio Democrático, Barcelona: RBA, 2005.

${ }^{29}$ La Iberia (9 marzo 1870)

${ }^{30}$ La Esperanza (18 julio 1870). Una historia detallada de la guerra franco-prusiana encontramos en el clásico trabajo de M. HOWARD, The Franco-Prussian war, Londres: Methuen, 1981. Para una visión de conjunto, más actual, podemos ver en el monográfico "La Guerra Franco-Prusiana (I).El ocaso de Napoleón III". Desperta Ferro: Historia moderna. n ${ }^{\circ} 13$. 2014. Sobre la figura y personalidad de Bismark; J. STEINBERG, Bismarck: A life. Oxford: Oxford University Press, 2011 y ya clásico trabajo de Emil LUDWIG Bismark: Historia de un luchador, Barcelona: Juventud,1972.
} 
23 de julio y se mismo día, desde el Palacio de Saint-Cloud, la Emperatriz se dirigió a los oficiales de la Marina para animarles a la victoria. Pero la agitación de París hizo que volviera de nuevo a las Tullerías. La Regente rezó en la parisina Iglesia de Nuestra Señora de la Victoria, por el triunfo de las armas francesas. El diario Libertè atribuía entonces a Eugenia de Montijo esta profética afirmación: "La solución de la guerra debe ser la victoria de los ejércitos franceses. Una paz firmada después de una derrota sería la muerte de la dinastía napoleónica" ${ }^{31}$. No se equivocaba.

De nuevo la actividad de la Montijo volvía a ser intensa. La Prensa española no escatimó elogios hacia su ilustre compatriota aplaudiendo las "pruebas de su extraordinario ánimo" ante las difíciles circunstancias que atravesaba el Imperio francés ${ }^{32}$. Especialmente aplaudida fue la proclama de la Emperatriz-regente dada el 7 de agosto en las Tullerías, tras el desastre de la batalla de Wissemburgo, en la que a pesar de reconocer las derrotas que estaban sufriendo en la guerra, animaba a la unión del país en el camino a la victoria y en una sola bandera, que sería la del honor nacional: "fiel a mi misión y mi deber, me veréis siempre la primera en el peligro para defender siempre el pabellón de Francia" 33 . Sin embargo, para el diario democrático La Discusión, ni las apelaciones de Napoleón al patriotismo de sus súbditos ni las proclamas de la Regente, servían ya para frenar la incuestionable victoria prusiana ${ }^{34}$. Pero lo cierto es que la mayor parte de la Prensa madrileña aplaudió en esos días difíciles para la vecina Francia, la energía y presencia de ánimo de la Emperatriz Eugenia que "al fin es española"35. El Imparcial 1legó a escribir que Eugenia era la única que conservaba el dominio y la sangre fría necesaria ante la compleja situación ${ }^{36}$.

Por otro lado, la retirada de tropas francesas de Roma a comienzos del mes

${ }^{31}$ La Discusión (31 julio 1970). Diario portavoz del Partido Democrático y de José María Rivero. Posteriormente y ya en su segunda época defiende las posiciones del Partido Radical afín al republicanismo. En este periodo se presenta abiertamente como antiamadeísta. Información más detallada sobre este periódico encontramos en

http://hemerotecadigital.bne.es/details.vm?q=id:0002126031\&lang=es

${ }^{32}$ La Correspondencia Universal (8 agosto 1870). Era un periódico noticioso -subtitulado "independiente"- que se definía como "diario de la familia, órgano de la verdad y celoso defensor de los altos intereses morales y materiales del país". Se publicó en 1870 y fue un claro opositor a Amadeo de Saboya. Comenzó titulándose sólo La Correspondencia lo cual generaba equivoco con el exitoso La Correspondencia de España. Puede verse;

http://hemerotecadigital.bne.es/details.vm?q=id:0029016657\&lang=es

${ }^{33}$ Proclama reproducida en el diario progresista La Nación, La Regeneración y en el Diario Oficial de Avisos de Madrid (8 agosto 1870)

${ }^{34}$ La Discusión (10 agosto 1870).

${ }^{35}$ La Época (10 agosto 1870).

${ }^{36}$ El Imparcial (9 agosto 1870). Comenzó a publicarse en 1867 y es el periodo más influyente durante el Sexenio Democrático. Era de carácter informativo aunque apoyó claramente a Amadeo I de Saboya. Puede verse; http://hemerotecadigital.bne.es/details.vm?q=id:0000189234\&lang=es 
de agosto para reforzar el frente alemán - tan contraria a la voluntad de la propia Eugenia- motivó el escrito que un grupo de diputados católicos hizo llegar a la Emperatriz en el que le animaban a reposicionar el papel que debía tener Francia "contra los encarnecidos enemigos del catolicismo"37. La evacuación de Roma por las tropas francesa había causado una impresión dolorosa en los periódicos católicos que en España abanderaba La Esperanza. El periódico reproduce una carta fechada el 14 de agosto en la que incide en la influencia que el catolicismo de la Regente debía tener en lo que se consideraba una decisión equivocada del Emperador. Los católicos y sobre todo los españoles, abrigaban en ella una esperanza $^{38}$. Para Alejo Raseny, firmante de la carta, la derrota gala era obra de la providencia por haber coincidido con el abandono de Roma de sus tropas. El carácter español y católico de la Montijo, se convertía de nuevo en el signo distintivo de la visión que de ella se ofrecía.

Todo parecía perdido. La Época adelantó la noticia, recogida de correspondencia de París: Napoleón III había hecho llegar a Eugenia su abdicación en la idea de que obrase según lo dispuesto antes de su partida ${ }^{39}$. La Esperanza también se hizo eco del rumor. Solo un día después, el Diario Oficial de Avisos de Ma$d r i d$, en informaciones recogidas desde el extranjero, publicaba que en Francia se había proclamado la República ${ }^{40}$. En las fortificaciones de París trabajaba ya un ejército de obreros y desde el cuartel general de Metz, las noticias no eran buenas. En apenas cuatro semanas, las tropas prusianas se habían apoderado de la Alsacia y la Lorena. Pero aun así Eugenia mantenía, con su actitud "los ánimos de esperanza del triunfo" ${ }^{\prime 1}$. Según se contaba, Eugenia enviaba a los coches de palacio para recoger heridos en la estación de ferrocarril aunque el periódico satírico Gil Blas se mofó de esta iniciativa ${ }^{42}$. Pero en general la Prensa española seguía aplaudiendo la fortaleza de espíritu de su noble compatriota de la que destacaban su fortaleza incansable y el cumplimiento de sus altos deberes como soberana. El alfonsino La Época, La Política y La Correspondencia Universal fueron quizá los diarios que lideraron este apoyo incondicional a la Regente incidiendo en sus

\footnotetext{
${ }^{37}$ Reproducido en La Nación (10 agosto 1870)

${ }^{38}$ La Regeneración (22 agosto 1870)

${ }^{39}$ La Época (12 agosto 1870).

${ }^{40}$ Diario Oficial de Avisos de Madrid (17 agosto 1870). Es el periódico continuador del Diario oficioso de Nipho. http://hemerotecadigital.bne.es/details.vm?q=id:0000192519\&lang=es

${ }^{41}$ La Época (17 agosto 1870).

${ }^{42}$ La Correspondencia de España (25 agosto 1870), La Correspondencia Universal (28 agosto 1870) y Gil Blas (28 agosto 1870). La Correspondencia de España era en esas fechas el diario de mayor tirada con cerca de 50.000 ejemplares. Había comenzado a publicarse en 1859 y representa todo un éxito en el nuevo modelo de prensa de empresa informativa. En estos años apoyaba claramente la opción montpensierista, entre otras causas debido a la amistad de su director, Manuel de Santa Ana con Antonio de Orleans.

http://hemerotecadigital.bne.es/details.vm?q=id:0000000000\&lang=es
} 
raíces españolas. Para ellos la Emperatriz pertenecía al grupo de mujeres que sabía cumplir con su deber si bien algunos diarios afines al republicanismo-federal, como La Igualdad, no compartían la influencia que Eugenia ejercía en la política del Imperio. La prueba la encontramos cuando, a raíz de la sugerencia de Eugenia al general Trochu -encargado de la misión de asegurar París como gobernador hasta la llegada del Emperador- para que presentase su dimisión, La Igualdad acuñase la expresión de "tan necia conducta es propia de la Montijo"43.

En esos días empezó a plantearse el futuro de Eugenia de Montijo si se confirmaban los desastres del ejército francés. Los rumores decían que había abandonado París. Los diarios españoles recogieron informaciones diversas, no siempre contrastadas, en las que se aludía a un futuro incierto para la Regente. En este sentido, España se presentó siempre como el destino indicado para nuestra compatriota. Su situación parecía angustiosa. ¿Escribió Eugenia a la Emperatriz Victoria para que mediara en la paz entre Francia y Prusia? Fue una información publicada en el Times que todos los periódicos de París, empezando por el oficial, se apresuraron a desmentir igual que hizo en España el liberal $L a I_{\text {Iberia }}{ }^{44}$. Otro rumor en esos, días hizo referencia a la protección que el gobierno francés, por inspiración de Eugenia, había dado a la entrada en España de los carlistas implicados en los inicios de la Tercera Guerra ${ }^{45}$. A este respecto Gil Blas volvía a cargar contra la Emperatriz al responsabilizarla de querer sembrar la Guerra Civil en el país que, según afirmaban, sería su refugio como exiliada. De nuevo catolicismo/religión/reacción/tradicionalismo se identificaban en la protagonista. Históricamente su apoyo a la causa del Duque de Madrid nunca se ha confirmado pero lo cierto es que la situación en España también se complicaba.

En los primeros días de septiembre de 1870 leemos las primeras informaciones de la derrota y "vergonzosa entrega" del ya ex-emperador Napoleón III. "El ejército ha sido derrotado y cautivo. Yo también estoy prisionero", es el texto del telegrama que que Napoleón escribió a la Regente ${ }^{46}$. Las últimas noticias de París confirmaban el nombramiento de un gobierno provisional compuesto por Thiers y Gambetta. Informaciones de la capital de Francia, apuntaban a que Eugenia conservaba "esa serenidad de ánimo que sólo se comprende en las almas de los héroes". La Correspondencia Universal publicaba ese 4 de septiembre, que según les refería un corresponsal, era una lástima "que Francia

\footnotetext{
${ }^{43}$ La Igualdad (29 agosto 1870). Periódico federal subtitulado “democrático-republicano". Había comenzado a publicarse en 1868 y lo hará hasta finales de 1874. Era el principal competidor de La Discusión. http://hemerotecadigital.bne.es/details.vm?q=id:0028707199\&lang=es

${ }^{44}$ La Iberia (24 agosto 1870) y La Esperanza (26 agosto 1870)

${ }^{45}$ La Correspondencia Universal, La Discusión y La Esperanza (2 septiembre 1870).

${ }^{46}$ F. DIAZ-PLAJA, Eugenia de Montijo, p.129.
} 
no confiase a la emperatriz el papel del hombre salvador de Francia ya que el emperador no era más que una vana mujerzuela" ${ }^{47}$. Con París sitiado y el cuerpo diplomático fuera de la capital ¿qué camino recorrería Eugenia? "Sola y abandonada en las Tullerías" -como leemos en el órgano del republicanismo-federal La Igualdad_"¿qué había de hacer sino resignarse con su suerte y emprender su marcha al extranjero?" ${ }^{48}$. Los primeros rumores (las noticias tomadas de la Prensa de esos días son muy confusas) apuntaban a que había atravesado la frontera francesa en dirección a Bélgica. Así lo publicó La Época el 5 de septiembre, al informar que la Emperatriz había telegrafiado a su madre, la condesa de Montijo, que todavía residía en Madrid. Sin embargo Eugenia había logrado salir de París en tren desde Serguiny hacia Deauville desde donde embarcó clandestinamente hacia la isla de Wright primero y a Portsmouth después. Al día siguiente se reunía con ella su hijo, que había salido del continente por Bélgica antes de la batalla de Sedám. El 11 de septiembre, La Correspondencia Universal había confirmado su partida ${ }^{49}$. El viaje despertó el interés de la Prensa española que llenó sus páginas con cartas en las que se describía el itinerario seguido hasta su llegada a la isla; para muchos Eugenia no era menos grande en su ostracismo que sentada en el trono ${ }^{50}$. Había comenzado el camino del exilio. El desastre militar y la "infame conducta de Napoleón" -según se reproduce en una carta publicada en La Discusión procedente de Burdeos- habían desencadenado la catástrofe. Solo Eugenia, único miembro español de la familia Bonaparte, se había comportado "varonilmente"

Como epitafio a su Regencia de 1870 podríamos acuñar la reflexión que fue publicada en el Diario Oficial de Avisos de Madrid y que recogía de un periódico de París;

Amigos y adversarios reconocen en la emperatriz Eugenia una fuerza de carácter y una elevación de sentimientos que honran sobremanera a la ilustre descendiente de los Guzmanes. ¡Que contraste con la conducta de su marido! ${ }^{52}$

Era el final de un Imperio y el comienzo de la República Francesa. Terminaban las águilas, las estatuas y los emblemas imperiales. Napoleón III estaba en poder de los

${ }^{47}$ La Correspondencia Universal (4 septiembre 1870)

${ }^{48}$ La Igualdad (6 octubre 1870).

${ }^{49}$ El diario monárquico La Época publicó el 17 de septiembre una carta en la que daba puntual información del viaje de la soberana, desde su salida del palacio de Tullerías en París a su llegada a Inglaterra. Detalles sobre el viaje y las muchas adversidades que pasó en su huida encontramos en Fernando DIAZ-PLAJA, Eugenia de Montijo, pp.128-135.

${ }^{50}$ Información detallada sobre el viaje de Eugenia a Inglaterra y sus primeros días de ostracismo en Hastings, encontramos en La Época (26 septiembre 1870), La Esperanza (1 octubre 1870) y La Época (7 octubre 1870).

${ }^{51}$ La Discusión (8 septiembre 1870)

${ }^{52}$ Diario Oficial de Avisos de Madrid (6 septiembre 1870). 
prusianos y Eugenia de Montijo en Inglaterra. Durante diecisiete años había sido Emperatriz de los franceses. Todos los periódicos monárquicos exaltaron la fortaleza con la que Eugenia había sobrellevado las nuevas circunstancias resaltando, de nuevo, el gran carácter de la española. Incluso el londinense Morning-Post -tal como recoge La Esperanza- prodigó todo tipo de elogios a la ya exiliada Emperatriz de los franceses: recordaba no solo su gracia, belleza y "encanto de maneras" sino, sobre todo, las obras de caridad que había impulsado en Francia y su asistencia los enfermos de cólera en la epidemia que había asolado al país. Destacó también la energía que había demostrado en los difíciles momentos de la Regencia que la hacían, a sus ojos, merecedora del aprecio de toda Inglaterra ${ }^{53}$.

Es quizá, la Prensa satírica la que sacó más punta a la nueva situación de la ya ex-emperatriz al ponerla en comparación con las circunstancias de la destronada Isabel II. Hemos visto ejemplos de La Flaca o Gil Blas pero es ahora, el periódico semanal satírico-burlesco, Tirabeque, que había comenzado a publicarse en Madrid e 1868, el que ridiculiza la situación de ambas mujeres publicando coplillas como la siguiente;

\section{LA CASA DE TÓCAME-ROQUE}

Muy buenos días Eugenia

-Felices, ¿Cómo te va?

-¡Cómo quieres que me vaya,

Isabelita, muy mal...!

-Vienes muy descolorida;

Yo no hago más que engordar,

Y eso que Paquito ahora

Tiene un carácter fatal

-¿Y Alfonsito?

-Está en la escuela

¿Y tu chico?

-Ahí fuera está

Jugando al toro.

-Y tu, ¿qué haces?

-Isabel vengo a buscar

un cuarto desalquilado.

-Chica, me temo que vas

a quedarte sin ninguno,

Sino andas lista ${ }^{54}$

\footnotetext{
${ }^{53}$ La Esperanza (8 octubre 1870).

${ }^{54}$ Tirabeque (11 septiembre 1870). Sobre la prensa satírica en este periodo resulta de interés; Marie-Angèle OROBON, "Una gloriosa revolución: Prensa satírica ilustrada e información mili-
} 


\section{CONCLUSIONES:}

La mayor parte de las informaciones que leemos en la Prensa sobre Eugenia de Montijo están recogidas de publicaciones francesas. En esta investigación, las fuentes más citadas son Le Moniteur Universel, el diario gubernamental Le Constitutionnel y Le Presse. Aunque también se han visto noticias tomadas de $L ' I n$ dépendance Belge y Le Gaulois. Diarios como los británicos Times y Morning Herald se utilizaron también como referencia. Indiscutiblemente, la línea editorial de estas publicaciones condicionará la percepción sobre nuestra protagonista. Los periódicos españoles reproducen, en muchos casos, los mismos textos de origen. También las cartas que se recibían desde el extranjero son una fuente principal para avanzar en la visión que se ofrecía en la Prensa sobre la condesa de Teba. En 1859 ya era habitual la información telegráfica y muchas noticias que llegaban a las redacciones, provenían de la agencia francesa Havas.

Pero ¿cuál es el balance que hacemos sobre la visión que se mostró de Eugenia de Montijo en las ocasiones en las que ocupó la Regencia del Imperio? Lo primero que tenemos que decir es que se trata de una perspectiva que cambia en función del momento histórico en el que se encuentra España. Durante sus breves regencias del 59 y del 65, la monarquía de Isabel II presentaba un escenario periodístico afín a la figura de la Emperatriz de los Franceses. Si bien es cierto que el régimen liberal español alternaba entre unionistas y moderados, las publicaciones analizadas presentan un punto de vista positivo de Eugenia de Montijo. De ella se valora -algo que se mantendrá en todo el periodo analizado- su fortaleza de espíritu e inagotable capacidad de trabajo. Diarios tan representativos del contexto isabelino como La Época o La Esperanza hacen hincapié en las dotes de gobierno de la Emperatriz: era una mujer intrépida y caritativa. Las fiestas de primavera, los bailes en Tullerías y banquetes políticos -aun teniendo en cuenta el atildado lenguaje decimonónico- quedaron relegados a mero acompañamiento de la obra social y política de Eugenia: sus iniciativas para la reforma de los establecimientos penitenciarios, donaciones económicas para socorros y sus incansables visitas a hospitales en la epidemia de cólera de 1865, fueron reconocidas por la Prensa en general. Con el triunfo de "La Gloriosa", la implantación de un nuevo modelo político y la profusión de nuevas publicaciones de tinte republicano, se abre el abanico de opiniones respecto a Eugenia

El carácter católico de Eugenia es otro de los atributos que más destaca la Prensa española de su personalidad. Ese catolicismo se convirtió en baza mediadora en la compleja política internacional francesa puesta de manifiesto en la "cuestión

tante (1868-1870)". Actas del XIII congreso de la Asociación de Historia Contemporánea, Cuenca: Ediciones de la Universidad de Castilla la Mancha, 2017. 
romana", derivada del proceso unificador italiano. Se presentó a Eugenia como un firme apoyo de los intereses temporales del catolicismo y en este punto tuvo el respaldo incondicional de periódicos como El Tiempo o La Correspondencia Universal. El periódico republicano-federal La Igualdad se mostró crítico con este posicionamiento de la Regente aunque fue el satírico barcelonés La Flaca el único que se atreverá a ridiculizar las convicciones íntimas de la Emperatriz.

Los diarios no escatimaron a la hora de elogiar a Eugenia como "ilustre compatriota”. A pesar de las divisiones ideológicas y enfrentamientos dialécticos que mantenían muchas publicaciones peninsulares, todos coincidían en cierta idea de "patriotismo" derivada de haber puesto en la cúspide imperial a una española descendiente de los Guzmanes. La Época, por ejemplo, se hizo eco en numerosísimas ocasiones de que Eugenia fuese granadina. Su dignidad de carácter era también una muestra de su españolidad en una percepción que quedaba reflejada en la valentía con la que había asumido el exilio de 1870 y que fue aplaudida por la Prensa política e informativa nacional liderada por La Correspondencia de España y El Imparcial, aun sabiendo que el Gobierno de Juan Prim apostaba por la opción amadeísta al trono de España. La Emperatriz de los franceses era nuestra "noble paisana": la heroica Eugenia. Ella no era la culpable de la política incierta y vacilante de los últimos años del Imperio.

Sin embargo el contrapunto con esa visión mayoritariamente positiva que se ofreció de las cualidades políticas de Eugenia de Montijo, la encontramos en la Prensa satírica y en los diarios de corte republicano federal que proliferaron en España tras el éxito de "La Gloriosa" y al calor del nuevo régimen de libertades. En este sentido destacó el periódico político-satírico Gil Blas que se atrevió, incluso, a mencionar murmuraciones acerca de la vida personal de la pareja imperial. También La Discusión y La Igualdad optaron por esta vía crítica acorde con su identidad política. Se trata de una consecuencia derivada de la línea editorial de estas publicaciones contrarias a la vigencia del propio modelo imperial.

La lectura de las referencias encontradas en la Prensa española sobre los periodos de Regencia de Eugenia de Montijo nos ha llevado a una necesaria reformulación de la idea que se tenía de lo femenino en el periodo del II Imperio Francés. Ella era mujer; con gracia, encanto, belleza, elegancia y afición a las modas. Hasta aquí estaría la concepción tradicional que -aún en un tiempo de fuerte emergencia de mujeres coronadas- se ofrecía del carácter intrínseco de un género débil. Pero el mérito que hemos encontrado en Eugenia, es que se le atribuyen cualidades que, en esa época, eran exclusivamente reconocidas como valores masculinos. Estas facultades se ponen muy de manifiesto con la derrota de agosto de 1870 y la posterior rendición de Napoleón III: en un tiempo marcado por la figura preeminente de Victoria de Inglaterra, la idea de "una mujer en el 
trono", impregna de algún modo la perspectiva política de género que se ofrece de la protagonista. Esta relación de lo individual con lo colectivo sitúa a la mujer como objeto historiográfico: el hecho biológico, acompañado de la construcción socio-cultural de las décadas de 1850 y 1860 , nos lleva a entender la microbiográfica, como método para hacer historia.

\section{BiBLIOGRAFÍA}

Almudena de ARTEAGA, Eugenia de Montijo, Barcelona: Ed. Martínez Roca, 2000.

Octave AUBRY, Eugenia de Montijo, Barcelona: Joaquín Gil, 1943.

R. BELLET, Presse et journalisme sous le Second Empire, París: Armand Colin, 1967.

J. CHAVES PALACIOS y F. LÓPEZ MORA, El Segundo Imperio Francés (1852-1870),

Córdoba: Servicios de Publicaciones de la Universidad de Córdoba, 2012.

Antonio CHECA GODOY, El ejercicio de la libertad. La Prensa española en el Sexenio Revolucionario (1868-1874), Madrid: Biblioteca Nueva, 2006.

Antonio CHECA GODOY, “Auge y crisis de la prensa satírica española en el Sexenio Revolucionario (1868-1874) “, El Argonauta español [En ligne], 13 | 2016, mis en ligne le 30 janvier 2016, consulté le 24 juillet 2020 ,

https://journals.openedition.org/argonauta/2335.

Fernando DÍAZ-PLAJA, Eugenia de Montijo, emperatriz de los franceses, Barcelona: Planeta, 1993.

D. DUFF, Eugenia de Montijo y Napoleón III, Madrid: Rialp, 1981.

Pilar EYRE, Pasión Imperial. La vida secreta de la Emperatriz Eugenia de Montijo, la española que sedujo a Napoleón III y conquistó Francia, Madrid: La Esfera, 2010.

P. GUIRAI y E. TEMIME, "L'Hisiorioarupliic dii Second Empire". Revue d'Histoire Moderne et Contemporaine, t. XXI. París, 1974.

Eugenio HARTZENBUSCH, Apuntes para un catálogo de periódicos madrileños desde el año 1661 al 1870, Madrid: Rivadeneira, 1894, 421 p. [edición facsímil de 1993, Madrid, S.L. Ollero y Ramos]

M. HOWARD, The Franco-Prussian war, Londres: Methuen, 1981.

José María JOVER, La era isabelina y el Sexenio Democrático, Barcelona: RBA, 2005.

Emil LUDWIG, Bismark: Historia de un luchador, Juventud: Barcelona, 1972.

I.MARGARIT, Eugenia de Montijo y Napoleón III, Madrid: Plaza\&Janés, 1999.

Marie- Angèle OROBON, "Una gloriosa revolución: Prensa satírica ilustrada e información militante (1868-1870)”. Actas del XIII congreso de la Asociación de Historia Contemporánea, Cuenca: Ediciones de la Universidad de Castilla la Mancha, 2017.

F. PAEZ-CAMINO y P. LLORENTE HERRERO, Francia: el Segundo Imperio y la Tercera República, Madrid: Akal, 1986.

Alejandro PIZARROSO, Historia de la Prensa, Madrid: Ramón Areces, 1994.

Imbert SAINT-AMAND, Napoleón III. Barcelona: Montaner y Simón Editores, 1898. 
J. STEINBERG, Bismarck: A life, Oxford: Oxford University Press, 2011

Juan B. VILAR, Los españoles en la Argelia francesa (1830-1914), Murcia: C.S.I.C. y Secretariado de Publicaciones de la Universidad de Murcia, 1989.

Gaceta de Madrid (timbre de periódicos): http://www.boe.es

\section{Hemerotecas:}

Hemeroteca Digital. Madrid: http://hemerotecadigital.bne.es/index.vm

Archivo Prensa Histórica. Ministerio de Cultura, Madrid: http://prensahistorica.mcu.es/

Biblioteca Nacional de España. Hemeroteca digital. Madrid:

http://hemerotecadigital.bne.es/index.vm

-Hemeroteca Municipal de Madrid:

http://www.memoriademadrid.es/buscador.php?accion=buscarAvanzado\&pagina $=\&$ busqueda_libre_02_tipo $=$ materia\&busqueda_libre_02 $=$ Hemeroteca $\% 20$ Municipal 


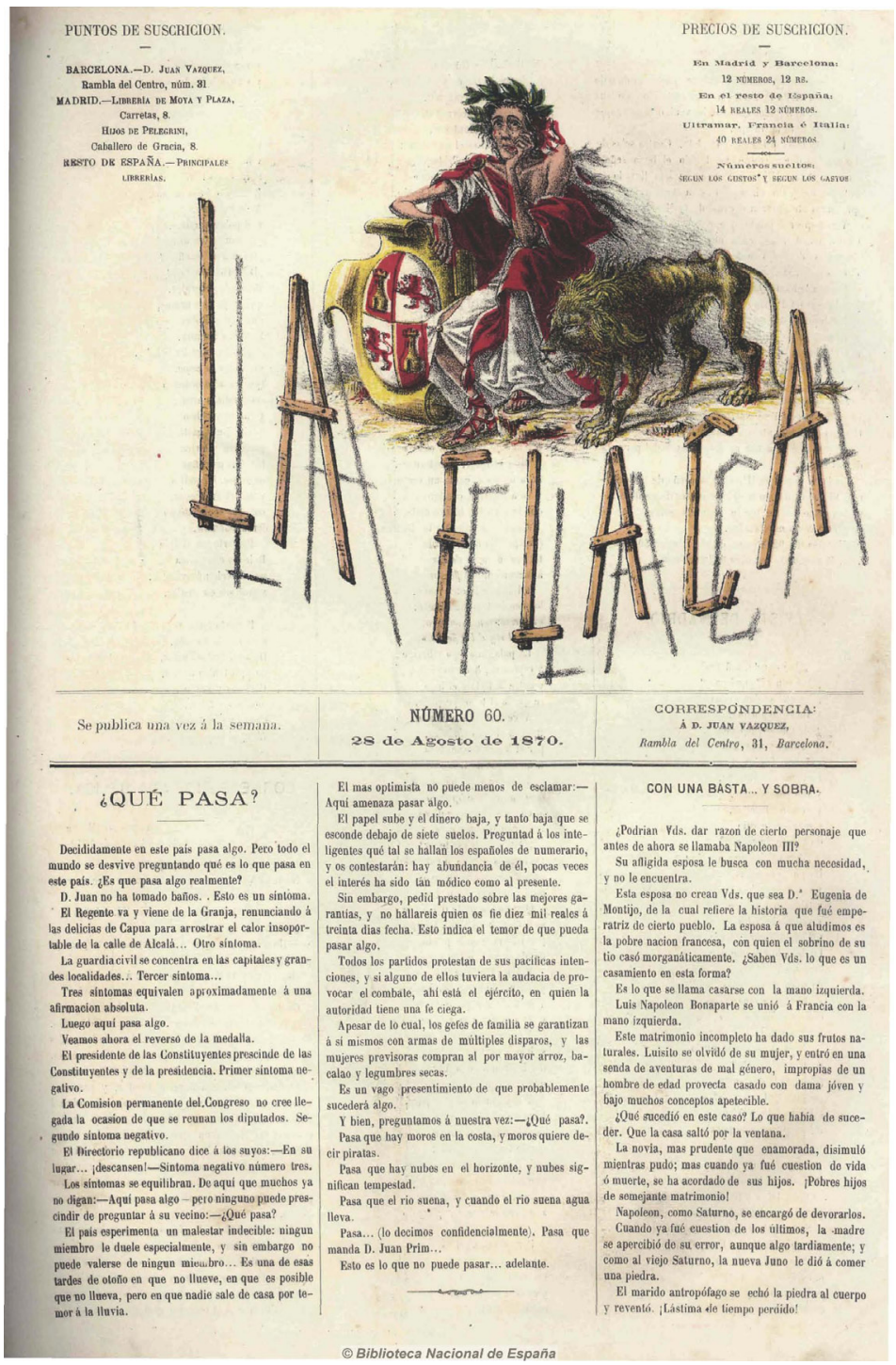


